\title{
CLINICAL PROFILE IN 100 CONSECUTIVE CASES OF PROSTATISM IN A RURAL HOSPITAL, LONI
}

\author{
P. Baviskar1, H. G. Vyas $^{2}$, Ketan Borole 3
}

${ }_{1}^{1}$ Professor, Department of Surgery, Rural Medical College, (A Constituent of Pravara Institute of Medical Sciences: Deemed University), Loni, Ahmednagar, Maharashtra.

2Professor, Department of Surgery, Rural Medical College, (A Constituent of Pravara Institute of Medical Sciences: Deemed University), Loni, Ahmednagar, Maharashtra.

3Postgradute Student, Department of Surgery, Rural Medical College, (A Constituent of Pravara Institute of Medical Sciences: Deemed University), Loni, Ahmednagar, Maharashtra.

\section{ABSTRACT}

\section{BACKGROUND}

Prostatism manifested by irritative and obstructive symptoms is an increasing challenge to diagnose and treat, as it is both bothersome and serious. A proper pre-operative assessment of size of prostate clinically, by DRE and by sonography is recommended.

\section{MATERIALS AND METHODS}

This prospective, non-randomised, controlled study was conducted on 100 patients with prostatism. The patients attending symptoms of prostatism and not a proven case of prostate cancer were included. After detailed clinical exam including DRE, sonographic examination was conducted. A transperineal needle biopsy was taken and sent for histological confirmation. Data obtained were correlated with clinical \& ultrasonographic findings.

\section{RESULTS}

The average age of incidence of Ca Prostate is higher than the average age for BPH. The commonest symptom of prostatism found is frequency (84\%) and urgency (80\%) followed by terminal dribbling (74\%). Digital Rectal Examination (DRE) was not found to be a reliable method of excluding Ca prostate. Ultrasonography also has limitations in excluding Ca prostate in cases with prostatism. Transperineal prostate biopsy can help diagnose cases of Ca prostate. The major complications after transperineal prostate biopsy procedure were significant pain (6\%) and severe haematuria (1\%).

\section{CONCLUSION}

The clinical profile of cases presenting at a Rural Hospital, Loni were studied in terms of age, symptoms, DRE and ultrasonographic findings. Prostatic cancer is a disease of advanced age group. The presentation is as in BPH with symptoms such as frequency, urgency and terminal dribbling. The high sensitivity is the key to early diagnosis. Ultrasonography is quite helpful in diagnosing $\mathrm{BPH}$, but does not offer real help and transperineal biopsy is much helpful in diagnosis.

\section{KEYWORDS}

Prostate, Prostatism, Irritative and Obstructive Symptoms, CA Prostate, BPH, Prostatic Biopsy.

HOW TO CITE THIS ARTICLE: Baviskar P, Vyas HG, Borole K. Clinical profile in 100 consecutive cases of prostatism in a rural hospital, Loni. J. Evolution Med. Dent. Sci. 2017;6(89):6214-6218, DOI: 10.14260/jemds/2017/1351

\section{BACKGROUND}

Prostatism affects the quality of life by its irritative and obstructive symptoms. Prostatism can be due to $\mathrm{BPH}$, malignancy of prostate, bladder calculi, chronic prostatitis, UTI, detrusor muscle weakness, neurological diseases like spinal cord injury. Indians' life expectancy is increasing and number of people seeking medical advice for bladder neck obstruction is increasing as well. About one third of men will develop prostatism of which the principle underlying cause is benign prostatic hyperplasia. Prostate cancer is the most commonly diagnosed non- cutaneous (visceral) cancer and

'Financial or Other Competing Interest': None.

Submission 29-09-2017, Peer Review 01-11-2017,

Acceptance 07-11-2017, Published 13-11-2017.

Corresponding Author:

Dr. H. G. Vyas,

Professor,

Department of Surgery,

Rural Medical College,

Loni, Ahmednagar.

E-mail: premharldpac@yahoo.co.in

DOI: $10.14260 /$ jemds $/ 2017 / 1351$ the second most common cause of death from cancer in males in US in 2012. If untreated, prostate enlargement can lead to complications such as acute urinary retention, recurrent UTI, bladder stone formation, renal failure, recurrent microscopic haematuria, bladder diverticula, and most importantly prostatic malignancy. Realising this, it is paramount to increase awareness and knowledge on prostatism to enable early diagnosis and treatment. A proper pre-operative assessment of size of prostate clinically and by sonography is recommended. DRE can provide erroneous results in predicting size, surface, consistency of prostate. DRE is still a basic step in the suspecting prostate cancer. ${ }^{1}$

Transabdominal USG has proved to be the most accurate predictor of actual prostate size. In addition, sonography provides information about post-void urine volume, hypoechoic lesions in prostate suggestive of malignancy of prostate, vesicle calculus, median lobe and also the state of kidney and ureters.

This study was conducted to depict the clinical profile of cases of prostatism and to find out silent/latent malignancy of prostate by transperineal prostate biopsy in patients coming to surgery OPD with complaints of prostatism. 


\section{MATERIALS AND METHODS}

Study Design

Case Series.

\section{Period of Study}

The present study was carried over two years' period from May 2010 to July 2012.

\section{Place of Study}

Pravara Rural Medical College and Hospital, Loni. DistAhmednagar.

\section{Number of Cases}

The study consists of 100 cases of Prostatism from general population coming to Surgery OPD.

\section{Patients Selection}

All patients with complaints of prostatism, over 50 years of age and willing.

\section{Exclusion Criteria}

Confirmed cases of Ca Prostate or those with deranged coagulation profile and those unwilling were excluded.

\section{Materials}

BARD-max core biopsy gun.

\section{Methods}

1. Detailed history taken.

2. Clinical examination of patient including Digital rectal examination (DRE) done.

3. Routine laboratory investigations- complete Haemogram with bleeding time and clotting time, Liver function tests, Renal function tests, urine routine and microscopy done.

4. Relevant special investigations including Ultrasonography of prostate and post-void urine volume.

5. Transperineal prostatic biopsy was taken after informed consent. Biopsy samples sent to pathology laboratory for reporting.

\section{Statistical Analysis}

Data was collected and tabulated in Microsoft office excel (2007). Statistical analysis was done by SYSTAT version 12 . Descriptive statistics used was count, mean, proportion, and inferences are drawn using " $\mathrm{Z}$ test" and correlations are proved using Chi-square test. Results obtained were compared with studies done by other scientists.

\section{RESULTS}

\begin{tabular}{|c|c|c|c|c|c|}
\hline \multirow{3}{*}{$\begin{array}{l}\text { Age } \\
\text { in } \\
\text { years }\end{array}$} & \multicolumn{5}{|c|}{ Biopsy Report } \\
\hline & BPH & $\begin{array}{c}\text { Ca } \\
\text { Prostate }\end{array}$ & Atypia & \begin{tabular}{|c|} 
In \\
conclusive/ \\
Failure of \\
Procedure
\end{tabular} & Total \\
\hline & No. & No. & No. & No. & No. (\%) \\
\hline $51-60$ & 13 & 0 & 0 & 0 & $13(13 \%)$ \\
\hline $61-70$ & 53 & 2 & 1 & 1 & $57(57 \%)$ \\
\hline $71-80$ & 25 & 3 & 0 & 0 & $28(28 \%)$ \\
\hline $81-90$ & 2 & 0 & 0 & 0 & $2(2 \%)$ \\
\hline Total & 93 & 5 & 1 & 1 & 100 \\
\hline $\begin{array}{c}\text { Mean } \\
\pm S D\end{array}$ & \begin{tabular}{|c}
67.64 \\
\pm \\
14.25
\end{tabular} & $\begin{array}{c}71.50 \pm \\
11.57\end{array}$ & $\begin{array}{c}65.5 \pm \\
0\end{array}$ & $\begin{array}{c}65.5 \pm \\
0\end{array}$ & $\begin{array}{c}67.60 \pm \\
16.47\end{array}$ \\
\hline \multicolumn{6}{|c|}{$\begin{array}{c}\text { Table 1. Correlation between Age and Biopsy Report in } \\
\text { Cases of Prostatism }\end{array}$} \\
\hline
\end{tabular}

Value of $\chi^{2}=0.49$, d.f. $=9, p>0.05$, not significant.

$\mathrm{BPH}$ is commonest/higher (57\%) in the age group of 6170 years with average age of 67.24 years. Ca prostate is common $(60 \%)$ in the age group of 71-80 years with average age of 71.50 years. Association of age with biopsy report was not statistically significant.

\begin{tabular}{|c|c|}
\hline Symptoms & No. of Cases (\%) \\
\hline Frequency & $84(84 \%)$ \\
\hline Urgency & $74(74 \%)$ \\
\hline Nocturia & $80(80 \%)$ \\
\hline Hesitancy & $42(42 \%)$ \\
\hline Weak stream & $42(42 \%)$ \\
\hline Terminal dribbling & $74(74 \%)$ \\
\hline Acute retention of urine & $16(16 \%)$ \\
\hline Table 2. Symptomatology Distribution of Prostatism Cases \\
\hline
\end{tabular}

Frequency (84\%) is the commonest symptom followed by nocturia (80\%), urgency (74\%), terminal dribbling (74\%), hesitancy (42\%), weak stream (42\%) and acute retention of urine $(16 \%)$ observed in the cases of prostatism.

\begin{tabular}{|c|c|c|}
\hline & & No. of Cases (\%) \\
\hline \multirow{2}{*}{ Consistency } & Firm & $93(93 \%)$ \\
& Hard & $7(7 \%)$ \\
\hline \multirow{2}{*}{ Surface } & Smooth & $92(92 \%)$ \\
& Irregular & $8(8 \%)$ \\
\hline \multirow{2}{*}{ Rectal Mucosa } & Free & $97(97 \%)$ \\
& Fixed & $3(3 \%)$ \\
\hline \multicolumn{2}{|c|}{ Table 3. DRE Findings of Enlarged Prostate in Cases of } \\
\multicolumn{2}{|c|}{ Prostatism } \\
\hline
\end{tabular}

In Ca prostate, prostate is hard, irregular, nodular, indurated and rectal wall fixed or free.

\begin{tabular}{|c|c|c|c|c|c|}
\hline $\begin{array}{c}\text { DRE } \\
\text { examination }\end{array}$ & \multicolumn{5}{|c|}{ Biopsy report } \\
\hline & BPH & $\begin{array}{c}\text { Ca } \\
\text { Prostate }\end{array}$ & Atypia & $\begin{array}{c}\text { Inconclusive } \\
/ \text { failure of } \\
\text { procedure }\end{array}$ & $\begin{array}{c}\text { Total } \\
(\%)\end{array}$ \\
\cline { 2 - 6 } & No. & No. & No. & No. & No. (\%) \\
\hline Positive & 4 & 4 & 0 & 0 & $8(8 \%)$ \\
\hline Negative & 89 & 1 & 1 & 1 & $92(92 \%)$ \\
\hline Total & $\mathbf{9 3}$ & $\mathbf{5}$ & $\mathbf{1}$ & $\mathbf{1}$ & $\mathbf{1 0 0}$ \\
\hline $\begin{array}{c}\text { Table 4. Correlation between Digital Rectal Examination } \\
\text { (DRE) and Biopsy report in Cases of Prostatism }\end{array}$ \\
\hline
\end{tabular}

DRE Positive - suspicious for Ca prostate.

DRE Negative - non-suspicious for Ca prostate.

Value of $\chi^{2}=189.34$, d.f. $=3, p<0.01$, highly significant.

By applying Chi-square test there is a highly significant association between DRE and biopsy report in cases of prostatism $(\mathrm{p}<0.01)$.

\begin{tabular}{|c|c|c|c|c|c|}
\hline \multirow{3}{*}{$\begin{array}{c}\text { USG } \\
\text { Findings }\end{array}$} & \multicolumn{5}{|c|}{ Biopsy report } \\
\hline & BPH & $\begin{array}{c}\text { Ca } \\
\text { Prostate }\end{array}$ & Atypia & \begin{tabular}{|c} 
Inconclusive \\
/ failure of \\
procedure
\end{tabular} & Total \\
\hline & \begin{tabular}{|l|} 
No. \\
\end{tabular} & (No.) & (No.) & No. & No. (\%) \\
\hline $\begin{array}{c}\text { Prostato- } \\
\text { megaly }\end{array}$ & 90 & 1 & 1 & 1 & $93(93 \%)$ \\
\hline $\begin{array}{l}\text { Prostato- } \\
\text { megaly with } \\
\text { altered echo }\end{array}$ & 3 & 4 & 0 & 0 & $7(7 \%)$ \\
\hline Total & 93 & 5 & 1 & 1 & 100 \\
\hline
\end{tabular}

Table 5. Correlation between Ultrasonography Findings of Prostate and Biopsy Report 
Prostatomegaly with altered echostructure: suspicious of Ca prostate.

Value of $\chi^{2}=29.07$, d.f. $=3, \mathrm{p}<0.01$, highly significant.

By applying Chi-square test there is a highly significant association between USG findings and biopsy report in cases of prostatism $(\mathrm{p}<0.01)$.

$96.77 \%$ cases of $\mathrm{BPH}$ showed prostatomegaly findings, only $1 \%$ of $\mathrm{Ca}$ prostate cases showed prostatomegaly findings, $1.07 \%$ of atypia cases showed prostatomegaly findings and $1.07 \%$ of Inconclusive/failure of procedure showed prostatomegaly findings.

\begin{tabular}{|c|c|c|c|c|}
\hline \multicolumn{2}{|c|}{ Severe Haematuria } & \multicolumn{2}{|c|}{ Significant Pain } & Fever \\
\hline \multicolumn{2}{|c|}{ No. (\%) } & \multicolumn{2}{|c|}{ No. (\%) } & No. (\%) \\
\hline \multicolumn{2}{|c|}{$1(1 \%)$} & & $6(6 \%)$ & $0(0 \%)$ \\
\hline \multicolumn{5}{|c|}{$\begin{array}{c}\text { Table 6. Major Complications after Transperineal Biopsy } \\
\text { Procedure in Cases of Prostatism } \\
\end{array}$} \\
\hline $\begin{array}{c}\text { BPH } \\
\text { No. (\%) }\end{array}$ & \multicolumn{2}{|c|}{$\begin{array}{c}\text { Ca Prostate } \\
\text { No. }(\%)\end{array}$} & Atypia & Inconclusive \\
\hline $9393 \%)$ & \multicolumn{2}{|c|}{$5(5 \%)$} & $1(1 \%)$ & $1(1 \%)$ \\
\hline \multicolumn{5}{|c|}{ Table 7. Final Diagnosis } \\
\hline
\end{tabular}

\section{DISCUSSION}

\begin{tabular}{|c|c|}
\hline STUDY & Average Age for Prostate Cancer \\
\hline Hankey B F et al $^{2}$ & 70 years \\
\hline Shaker S J et al $^{1}$ & 69.6 years \\
\hline Ries et al $^{3}$ & 68 years \\
\hline Present Study & 71.83 years \\
\hline \multicolumn{2}{|c|}{ Table 8. Age Incidence in Prostate Cancer } \\
\hline
\end{tabular}

The average age of incidence of Ca Prostate in our study was 71.8 years and $60 \%$ patients of CA prostate in age group $71-80$ yrs. BPH is commonest/higher (57\%) in the age group of 61-70 years with average age of 67.24 years.

These findings were confirmed with those of Hankey B F et al who has shown the average age at the time of diagnosis of Ca prostate is 70 yrs. Shaker S J et al in the study of 213 cases found average age of 69.6 years, whereas Ries et al found average age of diagnosis of Ca prostate is 68 years with $63 \%$ diagnosed after the age of 65 years. Shrivastava et al found the average age of BPH between 51-70 years in 75\% cases where McLister in study of 372 cases had found average age of 67 years.

In our study, commonest symptom of presentation of patients was frequency (84\%) followed by nocturia $(80 \%)$, urgency \& terminal dribbling (74\%), hesitancy \& weak stream (42\%) and acute retention of urine (16\%).

Miller $^{4}$ (1965) quoted 80\% incidence of frequency while Michell stated 75\%. Boyle P et al ${ }^{5}$ (2003) stated prevalence of nocturia $78 \%$. Miller (1965) quoted only $12 \%$ incidence of urinary retention.

Higher incidence of retention of urine (16\%) and hesitancy and weak stream (42\%) noted in our study, is because of ignorant rural old people who neglected irritative symptoms of prostatism \& attended OPD after development of obstructive symptoms of prostatism.

\begin{tabular}{|c|c|}
\hline STUDY & Frequency (\%) \\
\hline Miller $^{4}$ & 80 \\
\hline Michell $^{\text {Moyle P et al }}{ }^{5}$ & 75 \\
\hline Boyent Study $^{2}$ & 78 \\
\hline \multicolumn{2}{|c|}{ Table 9. Frequency in Prostatism } \\
\hline
\end{tabular}

DRE is the oldest and the oldest most commonly used screening test for prostate cancer and its use has been recommended by several expert groups, including the American Cancer ${ }^{6}$ and the American Urological Association. ${ }^{7}$

In present study, 100 cases of prostatism coming to Surgery OPD underwent DRE examination. On DRE examination $93 \%$ cases were firm consistency, 7\% cases were hard in consistency; $92 \%$ cases were smooth in surface and $8 \%$ cases had irregular surface; $97 \%$ cases had no involvement of rectal mucosa while $3 \%$ cases were suspected to have involved rectal mucosa. In Ca prostate, prostate is hard, irregular, nodular, indurated and rectal wall may be fixed or free.

\begin{tabular}{|c|c|c|c|c|}
\hline & & DRE & BIOPSY & \\
\cline { 2 - 5 } & Positive & Negative & Ca Prostate & BPH \\
\hline Richert Boe et al $^{8}$ & 31 & - & $18(58 \%)$ & - \\
\hline${\text { Richard BT et } \mathrm{al}^{9}}^{9}$ & 888 & - & $364(41 \%)$ & - \\
\hline Shaker SJ et al ${ }^{1}$ & 41 & 172 & $25(60 \%)$ & 185 \\
\hline El Imam et al $^{10}$ & 54 & 140 & $26(48.1 \%)$ & 154 \\
\hline Present Study & 8 & 92 & $4(50 \%)$ & 93 \\
\hline
\end{tabular}

Table 10. Correlation between Digital Rectal Examination (DRE) and Biopsy Report in Cases of Prostatism

In our study on Digital Rectal Examination, only 8 cases were suspected as Ca prostate and 92 Cases suspected as Benign Prostatic Enlargement. On biopsy, out of 8 suspected cases of Ca prostate, only 4 cases (50\%) confirmed as Ca prostate. Out of 92 suspected cases of benign Prostatic Hypertrophy, 89 cases confirmed as Benign Hypertrophic Prostate, 1 case found to have Ca prostate, 1 case Prostatic Atypia and 1 case had Inconclusive report.

These findings were confirmed with those of Richert Boe et al. who detect $58 \%$ of prostate cancer on DRE. Richard B Thompson et al. suspected 888 cases of Ca prostate on DRE and confirmed only 364 (41\%) cases. Shaker SJ et al. diagnosed $60 \%$ cases of Ca prostate on DRE, whereas El Imam et al. $48 \%$ cases of Ca prostate.

\begin{tabular}{|c|c|c|c|c|}
\hline & \multicolumn{2}{|c|}{ Ultrasonography } & \multicolumn{2}{c|}{ Biopsy } \\
\cline { 2 - 5 } & $\begin{array}{c}\text { Prostato } \\
\text { megaly }\end{array}$ & $\begin{array}{c}\text { Prostatomegaly } \\
\text { With Altered } \\
\text { Echotexture }\end{array}$ & BPH & $\begin{array}{c}\text { Ca } \\
\text { Prostate }\end{array}$ \\
\hline $\begin{array}{c}\text { Richard } \\
\text { BT et al }\end{array}$ & - & 591 & - & $\begin{array}{c}326 \\
(55 \%)\end{array}$ \\
\hline Tang et al11 & 232 & 240 & 310 & $\begin{array}{c}162 \\
(67.5 \%)\end{array}$ \\
\hline $\begin{array}{c}\text { Manjeet } \\
\text { Singh et al12 }\end{array}$ & 65 & 23 & 62 & $\begin{array}{c}11 \\
(47.8 \%)\end{array}$ \\
\hline $\begin{array}{c}\text { Present } \\
\text { Study }\end{array}$ & 93 & 7 & 94 & $\begin{array}{c}4 \\
(57.14 \%)\end{array}$ \\
\hline $\begin{array}{c}\text { Table 11. Correlation between Ultrasonography (USG) and } \\
\text { Biopsy Report in Cases of Prostatism }\end{array}$ \\
\hline
\end{tabular}

In present study, on Ultrasonography of prostate, only 7 cases suspected as prostate cancer and rest 93 cases suspected as Benign Prostatic Enlargement. On Prostate biopsy, out of 7 suspected cases of prostate cancer, 4 cases (57.1\%) confirmed as having Ca prostate and remaining 3 cases found to have BPH. Out of 93 suspected cases of Benign prostatic enlargement, 90 cases confirmed as Benign Prostatic hyperplasia, 1 Case confirmed as Ca prostate, 1 case found to have Prostatic atypia and remaining 1 case had inconclusive report. 
These findings were compared with those of Richard B. Thompson et al who suspected 591 cases to have Ca prostate on Ultrasonography and confirmed only 326 cases (55\%) by biopsy. Tang et al studied 472 cases for screening of Ca prostate, 240 Cases found to have hypoechoic nodule on ultrasonography out of which $162(67.5 \%)$ cases confirmed Ca prostate on biopsy. Manjeet Singh et al found 23 cases of altered echotexture in prostate and out of which 11 (47.8\%) cases confirmed to have Ca prostate.

\begin{tabular}{|c|c|c|c|}
\hline Complications $\rightarrow$ & $\begin{array}{c}\text { Severe } \\
\text { Haematuria }\end{array}$ & $\begin{array}{c}\text { Significant } \\
\text { Pain }\end{array}$ & Fever \\
\hline Novella et al $13^{13}$ & --- & $2.2 \%$ & --- \\
\hline Ficarra et al $^{14}$ & $0.4 \%$ & --- & $0.6 \%$ \\
\hline Galfano et al $15^{15}$ & $0.4 \%$ & $1-6 \%$ & $0-1 \%$ \\
\hline Kawakami et al $^{16}$ & $0.4 \%$ & --- & $0.8 \%$ \\
\hline Present Study & $1 \%$ & $6 \%$ & $0 \%$ \\
\hline \multicolumn{2}{|r|}{$\begin{array}{r}\text { Table 12. Major Complications after } \\
\text { Transperineal Prostate Biopsy }\end{array}$} \\
\end{tabular}

Mild complications are relatively common, major complications are very rare after prostate biopsy. Most of the series reporting on transperineal prostate biopsy provide data concerning the complications related to the procedure. According to those data, Transperineal biopsy is a safe procedure.

In present study, the complications seen on transperineal prostate biopsy are severe haematuria $(1 \%)$, significant pain (6\%). These findings confirmed with Novella et al who found $2.2 \%$ cases of significant pain after transperineal prostate biopsy. Ficarra et al and Kawakami et al found severe haematuria in $0.4 \%$ cases and fever in $0.6 \%$ and $0.8 \%$ cases in respective studies. Galfano et al studied cases of transperineal prostate biopsy and found $0.4 \%$ cases with severe haematuria, $1.6 \%$ cases of significant pain $0-1 \%$ cases of fever.

\begin{tabular}{|c|c|c|c|}
\hline & Total Cases & BPH & Ca Prostate \\
\hline Owayo et al $^{1}$ & 292 & 160 & $82(28 \%)$ \\
\hline Shaker S J et al $^{1}$ & 213 & 169 & $41(19 \%)$ \\
\hline El Imam et al $^{10}$ & 194 & 140 & $54(54 \%)$ \\
\hline Present Study & 100 & 93 & $5(5 \%)$ \\
\hline \multicolumn{4}{|c|}{ Table 13. Final Diagnosis } \\
\hline
\end{tabular}

In our study, after transperineal prostate biopsy of 100 cases of prostatism, only $5 \%$ cases detected as Ca prostate and remaining 93\% were found as $\mathrm{BPH}$. One patient diagnosed as Prostatic atypia and one as inconclusive. Both these patients advised repeat biopsy after 6 weeks.

These findings were compared with Owayo et al who studied 292 cases and found $28 \%$ Ca prostate. In the study of 213 cases of Shaker S et al, 19\% found Ca prostate where as El Imam et al diagnosed 54\%.

\section{Summary}

Prostatism is one of the commonest major urological problem which surgeon has to treat.

A proper pre-operative assessment of size of prostate, clinically and sonographically is necessary; similarly, to detect silent/latent malignancy of prostate, prostate biopsy also necessary.

In present study, 100 cases of prostatism underwent clinical evaluation. Routine examination was followed by ultrasonographic examination and prostate biopsy and correlated clinicopathologically. The prostate biopsy was done by BARD-max core biopsy needle through transperineal route.

\section{The Study was carried over for a Two-Year Period-}

1. The average age of incidence of Ca Prostate in present study was 71.8 years and $60 \%$ patients of Ca prostate in age group $71-80$ years while BPH is commonest/higher $(57 \%)$ in the age group of $61-70$ years with average age of 67.24 years.

2. In present study, the commonest symptom of prostatism was frequency $(84 \%)$ and urgency $(80 \%)$ followed by urgency (74\%) and terminal dribbling (74\%) but hesitancy, weak stream and acute retention of urine (16\%) were observed in significant proportion of rural Indian patients of prostatism.

3. On Digital Rectal Examination (DRE) of 100 cases of prostatism, 8 cases found hard, irregular prostate and suspected as malignancy of prostate. But after prostate biopsy of these 8 cases, only 4 cases (50\%) confirmed as Ca prostate.

4. On Ultrasonography of 100 cases of prostatism, 7 cases found prostatomegaly with altered echostructure and suspected as malignancy of prostate. After prostate biopsy of these 7 cases, only 4 cases $(57.1 \%)$ confirmed as Ca prostate.

5. The major complications after transperineal prostate biopsy procedure were significant pain $(6 \%)$ and severe haematuria (1\%).

\section{CONCLUSION}

The Conclusions Drawn from Present Study-

- $\quad$ BPH (93\%) is the most common cause of prostatism but Ca prostate $(5 \%)$ is the most feared one.

- In this study, Ca prostate was found in $7^{\text {th }}$ decade of life in males while BPH commonly seen in $6^{\text {th }}$ decade of life.

- Digital Rectal Examination (DRE) has little role in the screening for prostate cancer but it should not be omitted from the physical examination of patients, as $50 \%$ prostate cancers can be diagnosed by DRE.

- The Ultrasonography provides information about size of prostate, post-void urine volume and hypoechoic lesions in prostate suggestive of malignancy of prostate. It was efficient than DRE for diagnosis of prostate cancer.

- The transperineal prostate biopsy is a safe and minimal invasive procedure with a very low complication rate. It can be routinely done on an outpatient basis and rarely requires hospitalisation

\section{REFERENCES}

[1] Shaker SJ, Mohammad AM. Prostate-specific antigen versus digital rectal examination in the diagnosis of prostate cancer. DMJ 2008;2(1):80-90.

[2] Hankey BF, Feuer EJ, Clegg LX, et al. Cancer surveillance series: interpreting trends in prostate cancer-part 1: evidence of the effects of screening in recent prostate cancer incidence, mortality and survival rates. J Natl Cancer Inst 1999;91(12):101724.

[3] Ries LA, Melbert D, Krapcho M, et al. SEER Cancer Statistics Review, 1975-2005. NCI, Bethesda, 2011. 
[4] Miller L. Williams and Briggs "Problems in prostatic disease" advances in study of prostate. 1965: p. 2.

[5] Boyle P, Robertson C, Mazzetta C, et al. The prevalence of lower urinary tract symptoms in men and women in four centres. The UrEpik study. BJU Int 2003;92(4):409-14.

[6] Birkhoff JD, Wiederhorn AR, Hamilton ML, et al. Natural history of benign prostatic hypertrophy and acute urinary retention. Urology 1976;7(1):48-52.

[7] Eddy D. American Cancer Society. Guidelines for the cancer-related checkup: recommendations and rationale. CA Cancer J Clin 1980;30:194-240.

[8] Richert-Boe KE, Humphrey LL, Glass AG, et al. Screening digital rectal examination and prostate cancer mortality: a case-control study. J Med Screen 1998;5(2):99-103.

[9] Richard BT, Ira MF. A retrospective review of 2076 prostate ultrasonograms in one urology practice. The Permanente Journal 2000;4(1):17-23.

[10] Md. El Imam MA, Higazi NZ, Abuidris DO, et al. Prostate Specific Antigen versus Digital Rectal Examination as screening for ca prostate in Sudanese patients. Sudanese Journal of Public Health 2009;4(2):278-81.
[11] Tang J, Li X, Wang N, et al. Correlation between hypoechoic nodules on Ultrasonography \& benign hyperplasia in the prostatic outer gland. J Ultrasound Med 2005;24(4):483-8.

[12] Manjeet S, Feroze S, Baldev S, et al. Transrectal ultrasonography of prostate-correlation with histopathology. JK-Practitioner 2006;13(3):138-9.

[13] Novella G, Ficarra V, Galfano A, et al. Pain assessment after original transperineal prostate biopsy using a coaxial needle. Urology 2003;62(4):689-92.

[14] Ficarra V, Martignoni G, Novella G, et al. Needle core length is a quality indicator of systematic transperineal prostate biopsy. Eur Urol 2006;50(2):266-71.

[15] Galfano A, Noverra G, Lafrate M, et al. Prostate biopsy: the transperineal approach. Eau-Ebu Update Series 2007;5(6):241-9.

[16] Kawakami S, Okuno T, Yonese J, et al. Optimal sampling sites for repeat prostate biopsy: a recursive partitioning analysis of three-dimensional 26-core systematic biopsy. Eur Urol 2007;51(3):675-83. 